\title{
El amor a través de los ojos en la antigua poesía india de Amaru
}

\section{Love through the eyes in the ancient Indian poetry of Amaru}

\author{
SERGIO A. RENTERÍA ALEJANDRE \\ Centro de Estudios de Asia y África \\ El Colegio de México, \\ Ciudad de México, México \\ srenteria@colmex.mx
}

Resumen: Uno de los procesos estéticos que caracteriza la poesía de la India antigua es la mirada, la cual se ha convertido en el receptáculo de sentimientos y emociones dentro de la teoría literaria del rasa. Los ojos son el vehículo poético y el tópico más usado dentro de la poesía antigua de la India. En este desarrollo poético, existen elementos de análisis y creación literaria enmarcados en el método denominado rasa o "placer estético". Esta teoría literaria consiste en saborear la poesía a través de ocho sabores esenciales. El principal es el sabor del amor (śrngāararasa), el cual se divide a su vez en "el amor en la unión" (sambhoga) y "el amor en la separación" (vipralambha). Para que este proceso de amor surja y se pueda saborear, los amantes tienen que contemplarse. De aquí que mi trabajo se centre en la mirada. Mi objetivo principal es analizar algunos poemas de Amaru sobre este tópico para dilucidar, con el apoyo de las figuras retóricas y la resonancia poética, la importancia que tienen los ojos en la poesía de la India antigua.

Palabras clave: poesía india, teoría literaria, sentimiento estético, figuras retóricas, amor. 
Abstract: One of the aesthetic processes that characterize the poetry of ancient India is the gaze, which has become the receptacle of feelings and emotions into literary theory of rasa. The eyes are the most used poetic and topical vehicle into ancient Indian poetry. In this poetic development there are elements of literary analysis and creation framed in the method called rasa or "aesthetic pleasure". This literary theory consists of savoring poetry through eight essential flavors. The main one is the taste of love, which is divided in turn into "the love of union" (sambhoga) and "the love in separation" (vipralambha). For this love to emerge and be savored, lovers have to contemplate each other. My work focuses on this aspect, on the gaze. My main objective is to analyze some Amaru's poems on this topic and thus elucidate, with support of rhetorical figures and poetic resonance, the importance of the eyes in the poetry of ancient India.

Keywords: Indian poetry, literary theory, aesthetics feelings, figure of speech, love.

Citar como: Rentería, S. (2022). El amor a través de los ojos en la antigua poesía india de Amaru. Revista Internacional de Estudios Asiáticos, $1(1), 98-121$.

Fecha de recepción: 27-09-2021 | Fecha de aceptación: 10-11-2021 


\section{Introducción}

¿Quién no ha escuchado alguna vez la frase "los ojos son la ventana del alma"? A lo largo de la historia, muchos poetas y poetisas han hecho referencia a los ojos como medio de contacto entre el alma de los seres vivos con el mundo que los rodea para expresar el sentimiento del amor. Este era el tópico más importante de la poesía de la India antigua. Su estudio comienza en la lírica descrita en la literatura védica y en la literatura prácrita.

En este sentido, uno de los poetas sánscritos que recurre a este tópico es Amaru (circa 850 e.c.), quien, dentro de su obra Amarusataka, simplemente Śatakam, o bien "La centuria poética de amor", describe este afecto como una de las emociones universales que caracteriza a los seres humanos. Indiscutiblemente, Amaru es uno de los líricos más importante de la India antigua. Probablemente proveniente de Cachemira, cronológicamente debió estar próximo al siglo I e.c. Su obra pertenece a la lírica de la India antigua y se trata de una recopilación de cien versos.

Existen al menos cuatro recensiones de esta obra: una del sur de la India, otra del oeste, una de Bengala y una mezclada de estas tres. La recensión de Bengala es la que utilizo para traducir y comentar en este trabajo algunos poemas, publicada en la editorial Chaukamba de Varanasi. El número de versos no asciende exactamente a cien, sino que va desde 96 a 115. Sólo los primeros 51 versos son comunes a todas las recensiones y forman, por ello, el antiguo núcleo de la compilación.

El Amarusataka, también llamado Śataka, es una de las obras más importantes de la lírica erótica sánscrita. Esta obra de arte literaria destaca por el manejo de los tópicos, los procesos de la teoría del rasa y hasta los aspectos morfosintácticos y métricos que Amaru utiliza en cada poema. ${ }^{1}$

La pena y la nostalgia que se dan durante la separación de los amantes constituyen un tema preciso para analizar y comentar. Estos rasgos poéticos se cristalizan en los ojos de los amantes y su contacto con el mundo que los envuelve. Estas narraciones particulares, en el pensamiento de Amaru, se desarrollan dentro de los múltiples escenarios propios de

1 Mylius, Klaus. Historia de la literatura india antigua. (Madrid: Trotta. 2015). 156. Además, se puede consultar la traducción al español de esta obra: Amaru. Cien poema de amor. (Versión directa del sánscrito de Fernando Tola. Barcelona: Barral editores. 1971). 11-17. 
la lírica sánscrita. Esto se debe a que la mirada de los amantes conlleva una carga emocional llena de sentimientos y emociones que describe una poesía dulce y sutil. Por ello, el propósito de este trabajo es ofrecer un comentario sobre la poesía de Amaru, específicamente en el tópico de los ojos y, a través de ellos, la mirada de los amantes, quienes reflejan el amor en sus muy variadas manifestaciones. Este poeta es uno de los más representativos expositores de los amantes en la poesía sánscrita. ${ }^{2}$

Este análisis se sustenta en la teoría del rasa que, a través del șrnggārarasa o "el sabor de lo erótico", da la pauta para dilucidar estos tópicos que subyacen no sólo en la poesía sánscrita sino también en el pensamiento amoroso de Amaru.

\section{La teoría literaria del rasa}

El vocablo rasa resulta muy importante para entender el pensamiento de Amaru, ya que esta teoría literaria fue la base para construir su poesía. Desde sus inicios, en la obra literaria Rgveda, ${ }^{3}$ la palabra rasa se utilizó

2 De, Kumnar, Sushil. Ancient Indian erotics and erotic literature. (Calcuta: Firma K. L. Mukhopadhyay. 1969). 28.

3 El contenido principal de la obra Rgveda está constituido por himnos dedicados principalmente a los dioses y a las diosas, pero también a demonios, reyes, antepasados, hasta ciertos animales y entidades abstractas, escrito en lengua védica. El dios que más veces aparece es Indra, el dios del rayo, a él se le dedican alrededor de 250 himnos. Otro dios muy nombrado es Agni, el dios del fuego védico. Él es mensajero entre el mundo de los dioses y los seres humanos. También es el protector del hogar y conservador del fuego del sacrificio. En general, los dioses de este panteón védico no se encuentran caracterizados con mucha nitidez. El Rgveda está compuesto en lengua védica. Contiene alrededor de 1028 himnos divididos en diez libros llamados mandala. De acuerdo con los lingüistas y filólogos, su lugar de origen probablemente se sitúa en la región de Pakistán posiblemente alrededor del 1500 o 1200 a.e.c., aunque algunos indólogos proponen entre el 1700 y el 1200 a.e.c. como la fecha de su composición. Mylius, Klaus. Historia de la literatura india antigua. 34-36. 
para designar la leche de vaca, ${ }^{4}$ el agua, ${ }^{5}$ y el jugo de una planta, particularmente la planta del soma; ${ }^{6}$ incluso llega a simbolizar el semen, como potencia viril, ya que se ha considerado la quintaesencia del cuerpo humano. ${ }^{7}$ Dentro del Atharvaveda, ${ }^{8}$ el campo semántico-pragmático del término se acrecienta, porque significa fluido, néctar, licor o poción. ${ }^{9}$ Del Atharvaveda se toma la concepción de los ocho sabores u ocho rasa que caracteriza la teoría del placer estético dentro del teatro clásico. Asimismo, rasa se utiliza en el Ayurveda como la medicina tradicional de la India que derivada del Atharvaveda. En el Ayurveda, rasa hace referencia al resultado de la reacción química entre los metales y los minerales, así como sus componentes medicinales, es decir, las "esencias" curativas. ${ }^{10}$

4 Rgveda Samihitā. Vv. IV. Texto sánscrito, traducción al inglés y notas de H. H Wilson y Bhāṣya de Sāyaṇācārya. Editado y revisado con una exhaustiva introducción y notas de Ravi Prakash Arya K. L. Joshi. (Nueva Delhi: Primal Publications. 2016). Rgveda. I. 37. 5.

5 Rgveda. III. 48. 1.

6 Rgveda. IX. 6.6.

7 Rgveda. I. 105. 2.

$8 \mathrm{El}$ nombre del Atharvaveda deriva de las palabras atharvan que significa "sacerdote del fuego". Originalmente se llamaba Atharvāingirasa. Aquí añgiras también significa "sacerdote del fuego". Ambas denominaciones remontan a dos familias de sacerdotes. El significado posterior de atharvan es "hechizo benéfico" y el angiras "hostil". En este sentido, el Atharvaveda, escrito en lengua védica, es ante todo un compendios de fórmulas mágicas y hechizos. Esto explica el por qué luchó durante mucho tiempo por ser el cuarto Veda. El argumento fue que su contenido era impío y que, por tanto, sólo existía la trayī vidyā, el triple saber, es decir, el conocimiento de rẹc, sāman y yajus. No obstante, el Atharvaveda alcanzó una valoración mayor con el paso del tiempo, aunque nunca ha logrado equiparse completamente con el resto de los sambitā, lo que también refleja en la inferioridad de los comentarios eruditos que se le han dedicado. Sin embargo, sus últimos libros retoman algunos himnos provenientes del Rgveda. El Atharvaveda nos ha llegado en las recensiones śaunaka y paippalāda. Está dividido en 20 libros llamados kānda, que consta de 730 himnos alrededor de 6,000 versos. Mylius, Klaus. Historia de la literatura india antigua. 53.

9 Atharvaveda Sambitā. Vv. III. Texto sánscrito, traducción al inglés, notas e índice de versos de acuerdo con la traducción del inglés de W.D. Whitney y Bhāṣya de Sāyanāāārya. Editado y revisado por K. L. Joshi. (Nueva Delhi: Primal Publications. 2015). Atharvaveda. IV. II. 5.

10 Atharvaveda. IV. IV. 5. 
En el Mahābhārata, ${ }^{11}$ se utiliza como el condimento del gusto culinario y el deseo amoroso. Estos dos aspectos del término siempre se unirán para que sus rasgos esenciales produzcan la degustación, el sabor mismo y la acción de saborear dentro de la cocina y, por ende, dentro de la composición literaria. ${ }^{12}$ Este punto es muy importante porque destaca la percepción y lo percibido a través de los ojos, lo cual se mezcla con la acción de degustar, porque, en sentido estricto, se ejerce una acción degustativa de la experiencia vía la percepción visual del poeta.

En las Upanișads, ${ }^{13}$ principalmente en la Chāndogya, el término rasa adquiere un campo semántico más abstracto, ya que el rasa se convierte en una experiencia intoxicante del placer místico. ${ }^{14}$ Por ello, el rasa se vuelve "la fuente de gozo" que hace que uno se descubra a sí mismo cuando se bebe, entrando en contacto con la propia esencia humana: la razón y

11 El Mahābhārata es la epopeya más importante de la cultura literaria india y el poema épico más largo de la historia mundial de la literatura. Consta de 18 libros (parvan) y un libro 19 denominado el Harivarisa, que sirve de epílogo (khila). La obra abarca cerca de 106, 000 śloka en lengua sánscrita. Dentro de la métrica sánscrita, el verso śloka es el más usado y popular dentro de la literatura de la India antigua. Está constituido por cuatro hemistiquios de ocho sílabas cada uno, donde la quinta sílaba siempre debe ser corta y la sexta larga. La séptima sílaba debe ser corta en el segundo y cuarto hemistiquios; en el primero y tercero debe ser siempre larga. Este verso se estructura de la siguiente manera: primer hemistiquio: - - -/ $-\cup-/--/$, segundo hemistiquio: $--\cup / \cup \cup-/ \cup-/$, tercer pie hemistiquio: $\cup \cup-/-\cup-/--/$ y cuarto hemistiquio: $-U-/-\cup-/ \cup-/$. El verso śloka pertenece al grupo de los anuștubh. Posee muchas variantes a excepción de la sílabas quinta, sexta y séptima que siempre cumplen con la estructura del śloka. La composición final del Mahābhārata se situó entre los siglos XV y XVI. Sin embargo, de acuerdo con los datos más recientes, los indólogos sitúan esta obra entre 400 a.e.c y el 400 e.c. Mylius, Klaus. Historia de la literatura india antigua. 85.

12 Vyāsa. Mahābhārata. Traducido por Paul Wilmot, William J. Johnsom, Kathleen Garbutt, Alex Cherniak, Vaughan Pilikian, Adam Bowles, Justin Meiland, Alexandre Wynne y Kate Crosby. Vv. XV. (Nueva York: New York University Press. 2006). Mahābhārata. XII. CCCXLVII. 67.

13 Se conocen como Upanișads a más de 200 textos religioso-filosóficos de la tradición hinduista escritos en lengua sánscrita. De estos textos los más antiguos da$\tan$ del 800 a.e.c al 400 a.e.c., como el que cito en este trabajo, la Chändogya-upanișad. Mylius, Klaus. Historia de la literatura india antigua. 68.

14 Upanișads. Prólogo de Raimon Panikkar y edición de Daniel de Palma. (Madrid: Siruela. 2006). Chändogya-upanisad. I. 1. 3. 
el principio creador del ser individual. Desde esta perspectiva, rasa es el zumo esencial que, cuando se prueba, produce un placer, en el cual se vinculan las peculiaridades del placer sexual, del placer amoroso y del gozo extático. ${ }^{15}$.

A partir de las Upanișad y del Mahābhārata, rasa adquiere su esencia literaria. Siguiendo esta línea, Bharata, en su obra Nätyśástra ${ }^{16}$ retoma la esencia literaria y le da la acepción de "placer estético", utilizando la metáfora del arte culinario. Así el término rasa adquiere un significado estético a partir del arte culinario, como la esencia de la comida o la composición literaria, lo que le da sabor a un platillo o a una obra, es decir, lo que se conoce como la degustación literaria. ${ }^{17}$ Esta es la génesis del término rasa como una teoría literaria desarrollada dentro del teatro. Por ello, tomo el rasa como la configuración de diversos elementos clave de la estética literaria y el placer en la India para enmarcarlo en la construcción y el análisis de la poesía.

En efecto, el carácter literario del concepto de rasa o "placer estético", nace en el ámbito teatral teorizada en la obra Nātyśāstra, como lo describí en las líneas anteriores. Esto permite, entonces, entender que una representación teatral se puede "saborear", "disfrutar" o "degustar". Por ello,

15 Chantal Maillard y Óscar Pujol. Rasa, el placer estético en la tradición india. Varanasi, Indica Etnos. 1999.

16 El Nãtyśástra (S. II a.e.c. - S. II e.c.) es una obra muy importante escrita en lengua sánscrita que describe la teoría teatral. Su autor es Bharatamuni, quien podría identificarse con un ser histórico o bien un ser mitológico. Está estructurada en 38 capítulos y está escrito en su mayor parte en verso śloka y parcialmente en verso $\bar{a} r y \bar{a}$. Es una obra muy polémica porque tradicionalmente la génesis del teatro nace del dios Brahma, quien crea el teatro. De aquí que esta obra se considere el quinto Veda, porque su constitución está realizada a partir de los cuatro Vedas. Mylius, Klaus. Historia de la literatura india antigua. 144.

17 Bharata. Nātyaśāstra. Vv. IV. (Tratado de la India Antigua sobre la representación histriónica y la dramaturgia). Editado y traducido con una introducción y varias lecturas por Manomohan Ghosh. (Varanasi: Chowkhamba Sanskrit Series Office. 2009). Nāttyaśástra. VI. 31. 
es importante tomar en cuenta el significado inicial del término: "sabor" y luego, por extensión, "deleite, degustación, gozo, felicidad". Desde esta perspectiva, el sujeto (lector o espectador) queda inmerso en una experiencia de la estética degustativa. ${ }^{18}$ De acuerdo con lo anterior, el rasasütra o "la teoría del rasa" se produce a partir de un surgimiento (nispatti) del rasa mismo, es decir, se origina gracias a la conjunción (samyoga) de los determinantes (vibhāva), de los consecuentes (anubhāva) y de los estados mentales transitorios (vyabhicāribhāva). Continuando con la metáfora culinaria, la mezcla de las especias, es decir, de los estados mentales transitorios, de los determinantes y de los consecuentes, se efectúa en los procesos de la creación literaria, lo cual también sucede en la cocina.

Según apunta Bharata, al combinarse cada especia, esencia o jugo de cada una de los rasa da pie a un sabor delicioso o un sentimiento básico (sthāyibhāva), que tanto el lector como el espectador podrán degustar al leer o presenciar el drama. ${ }^{19}$ En otras palabras, el rasa resultará de un estado emocional surgido a partir de los sentimientos básicos. Estos sentimientos básicos (sthāyibhāva) son las disposiciones psicológicas permanentes de la naturaleza humana; Bharata enumera ocho estados emocionales básicos: el amor (rati), la risa (bāsa), la pena (śoka), la cólera (krodha), el entusiasmo (utsāha), el miedo (bhaya), la aversión (jugupsā) y la admiración (vismaya). ${ }^{20}$ Estos estados emocionales básicos, cuando se combinan como si fuesen las especias, harán surgir un determinado rasa. Por esta razón, el término rasa se entiende como "placer estético" o "estado emocional estético" ya que fundamenta sus procesos teóricos literarios en las emociones mismas.

Si seguimos el orden de los sthāyibhāva, los ocho rasa son lo erótico (śringāra), lo cómico (hāsya), lo patético (karuna), lo furioso (raudra), lo heroico (vīra), lo terrible (bhayānaka), lo repugnante (bibhatsa) y lo ma-

18 Maillard, Chantal y Óscar Pujol. Rasa, el placer estético en la tradición india. Prólogo de Raimon Panikkar. (Varanasi: Indica Etnos. 1999). 22.

19 Nātyśāstra. VI. 31.

20 Nātysástra. VII. 9-27. 
ravilloso (adbbuta).$^{21}$ El rasa más importante es el șringārarasa, o el sabor de lo erótico, porque los poetas como Amaru construyen sus pensamientos sobre este sabor y es el más utilizado por poetas y poetisas. Dentro del śringāra, se puede saborear el sentimiento básico del amor mezclado con otras especias.

De acuerdo con lo anterior, el concepto del amor, en términos literarios dentro de la noción de rasa, se entiende como "la unión pasional entre dos personas llamado kàma; este amor, que puede finalizar en alegría o en pena para todos los seres vivos, es, la mayoría de las veces, importante en las situaciones de la felicidad, e incluso de la infelicidad. Además, siempre está unido al aspecto social de los cuatro fines de la vida: dharma, artha, kāma y mokșa. ${ }^{22}$ Esta definición es muy relevante para entender la poesía de Amaru, porque se debe destacar el amor no sólo como una imagen literaria y mitológica representada en la lírica india sino también como un concepto que funciona en el ámbito social de la India antigua y que se estructura a partir de una partición emocional y sentimental del rasa. Esta división se debe entender a partir de los conceptos de preman, śrnigàra y kàma como concepciones de amor centrados en la teoría literaria del rasa. De acuerdo con la definición anterior del amor, el concepto de śrngāararasa se divide en dos partes: sambbhoga, o el amor en la unión, y vipralambha, o el amor en la separación. En este sentido, el samibhoga es la máxima expresión del amor, porque es cuando los amantes están unidos y pueden expresar mutuamente el sentido inherente del amor. Pero, como lo han expuesto varios retóricos indios, el verdadero amor se produce en el vipralaíbha. Sin duda, el Nātyaśāstra describe esta bifurcación del amor como los elementos bases para entender el sabor del amor. ${ }^{23}$

Los conceptos de sambhoga y de vipralambha a su vez tienen distintas divisiones. Sin embargo, para efectos de mi análisis, me enfocaré en un solo concepto, en el darśana, es decir, el ver. El ver no sólo es el comienzo del amor sino también el principio del primer acto de los amantes para

21 Nātyśāstra. VI. 15.

22 Nātyaśāstra. XXIV, 95-96.

23 Nātyaśāstra. VI. 45. 
gozar o padecer la inclemencia de las emociones y sentimientos. Por ello, el amor nace a partir de las miradas de los seres humanos, cuyo instrumento son los ojos. Además, estos pueden hacer sufrir a los amantes; por ejemplo, cuando se contempla al ser amado cuando se va.

\section{El amor a través de los ojos en la poesía de Amaru}

A partir de las referencias anteriores, me parece pertinente plantear la siguiente pregunta: ¿realmente son los ojos trasmisores del śringārarasa en la poesía de Amaru? Para responder este cuestionamiento, es importante considerar una serie de elementos que se relacionan con los ojos dentro de los procesos poéticos de la teoría literaria del rasa. Estos elementos permiten entender claramente los poemas, porque los ojos son el instrumento de una percepción intelectual, de la inteligencia que descubre cosas racionales e irracionales del mundo, es decir, ver es comprender lo que hay en el entorno y esto incluye los sentimientos y las emociones que se relacionan íntimamente con el amor. ${ }^{24}$ En este sentido, el amor, en los versos de Amaru, no aparece solo sino que está acompañado de otros sentimientos y emociones que se mezclan, igual a las especias, en los amantes y, como si fueran espejos, los ojos reflejan estos sentimientos volviéndose portadores del amor.

La función simple de los ojos que sienten y transforman lo que ven es algo que llega al sentido más profundo de los amantes en la poesía de Amaru. Los ojos que lloran y sufren no sólo lo hacen por un daño físico, sino también por un daño emocional, es decir, por amor. Por ello, Amaru describe los ojos como un instrumento delator tanto en las mujeres como en los hombres, dentro de las diferentes circunstancias amorosas. Un ejemplo de ello se encuentra en el siguiente poema, porque existen unos ojos que se expresan en el mundo de los sentimientos y que toman las palabras precisas para explicar ese amor tácito que sólo se puede percibir a través de los ojos. En este poema, Amaru muestra los sentimientos y la belleza de una hermosa mujer que, en los primeros versos del poema, se en-

24 Beristáin, Helena. Análisis e interpretación del poema lírico. (México: Universidad Nacional Autónoma de México. 2004). 32. 
cuentra en una transparencia sentimental cargada de una hermosa serenidad. ${ }^{25}$ Esta es una expresión propia de la poesía amorosa sánscrita clásica. En este caso, la mujer sólo busca a su amado a través de las palabras descriptivas del poeta Amaru, quien habla como parte del consecuente a través del imperativo "háblame" (en sánscrito kathaya) y esto hace que surjan los componentes esenciales de la teoría del rasa:

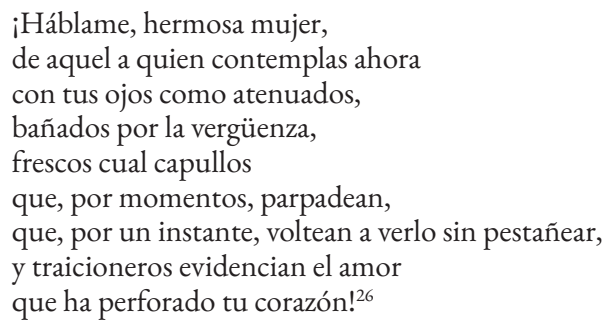

En este poema, las formas de expresión que califican los ojos (en sánscrito îșana) son fundamentales para comprender la actividad que realizan, pues clarifican la naturaleza del sentimiento básico del amor. Además, evidencian el sufrimiento de una hermosa mujer por un hombre en la separación. Estos calificativos se caracterizan por añadir un énfasis en el instrumento esencial como un determinante y permiten entender el amor (en sánscrito preman) que siente la mujer hacia el varón como el consecuente. En la percepción amorosa del verso, cuando dice: frescos cual capullos que, por momentos, parpadean, los capullos representan la metáfora (en sánscrito rüpaka) de un nacimiento. Este nacimiento se refiere

25 Gutiérrez, Salvador, Ordóñez. Comentario pragmático de textos literarios. (Madrid: Arco libros, S. L. 2000). 43

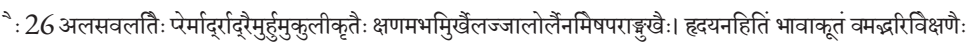
क्यथय सुकृती को उयं मुग्थे! त्वयाद्य वलिक्यते॥४॥ Amaru. Amarusatakam. Texto sánscrito con comentarios rasikasanjeevini de Arjunavarmadeva. Editado con comentarios y traducción en hindi por Shri Pradyumma Pandeya con una introducción de Shri Narayan Mishra. (Varanasi: Chowkhamba Sanskrit Series Office. 2000). Amaruśatakam. 4. 
a los capullos de las flores del loto que se abren y dan vida al amor, es decir, parpadean floreciendo. Se trata de una figura retórica muy común que en la poesía sánscrita.

Amaru plasma de manera semejante la intensidad del amor al referirse a los ojos de la mujer atenuados y bañados de vergüenza. Además, el poema a continuación califica los ojos como traicioneros (en sánscrito parāmukha). Este término se emplea en el terreno del amor, pues esto supone el sentido de delatar o evidenciar y, dentro de la cultura literaria india, esto causaba vergüenza (lajjā) a las mujeres y a los varones que sufrían por amor. En este poema, los ojos ocultan, pero a la vez evidencian el amor por aquel al que ahora contempla la bella mujer.

Además, cabe destacar que Amaru utiliza el metro harin̄ī en este poema, el cual pertenece al grupo llamado atyaști. El metro hariñi está dividido en cuatro hemistiquios de diecisiete sílabas cada uno. Este verso se estructura de la siguiente manera: primer hemistiquio: $\cup \cup \cup / \cup \cup-/---/-\cup-/ \cup \cup-/ \cup-/$, segundo hemistiquio: $\cup \cup \cup / \cup \cup-/---/-\cup-/ \cup \cup-/ \cup-/$, tercer hemistiquio: $\cup \cup \cup / \cup \cup-/---/-\cup-/ \cup \cup-/ \cup-/$ y cuarto hemistiquio: $\cup \cup \cup / \cup \cup-/---/-\cup-/ \cup \cup-/ \cup-/$. Este verso se estructura en cada hemistiquio por el grupo na o tribraquio $U \cup$ $\cup$, por el grupo $s a$ o antidáctilo $\cup \cup-$, por el grupo ma o moloso - -, por el grupo ra o crético - $U-$, por el grupo $s a$ o antidáctilo $U$ - - y por dos sílabas una breve la y otra larga ga, las cuales forman un pramānī o un yambo $U-{ }^{27}$.

Abordaré ahora el siguiente poema:

El varón que amas como a tu vida está sentado afuera cabizbajo

trazando distraído dibujos en la tierra,

27 Yedukondalu, K. Cassical Sanskrit Prosody. (Tirupati: Rashtriya Sanskrit Vidyapeetha. 2014). 486 . 
tus amigas se encuentran en ayuno con sus ojos hinchados de tanto llorar; todos los pericos, en sus jaulas, dejaron de hablar y reírse; sabes ahora cuál es tu condición, cruel mujer, deja tu orgullo. ${ }^{28}$

En este poema hay un varón que sufre por el orgullo de su amada enfurecida. Este retrato del varón como alguien que ha perdido el amor o que está a punto de hacerlo es un tópico muy común de la lírica sánscrita. En este sentido, los sentimientos corresponden a un amor fallido que se expresa a través de los ojos que miran fijamente la tierra mientras está el varón escribe trazos cabizbajo (en sánscrito likhannāste bbūmim bahiravanatah). Además, las amigas de ella la contemplan tristes con sus ojos dolientes (en sánscrito nayana) hinchados por tanto llorar (en sánscrito sakhyah satataruditocchünanayanāḥ). En este verso, una vez más, los ojos son la muestra del sufrimiento que, unido al amor, hacen que el poema sea una manifestación del sentimiento de un varón por una mujer. Existen, además, otros determinantes como el estar con la mirada clavada en el suelo, las amigas en ayuno o bien los pericos enjaulados que no hablan ni sonríen más por la pelea de los amantes que se podría interpretar como las personas que observan el desamor de la joven pareja.

En este poema, Amaru utiliza el metro síkharin̄in, el cual también pertenece al grupo llamado atyaști. el metro sikharin̄i está dividido por cuatro hemistiquios de diecisiete sílabas cada uno. Este verso se estructura de la siguiente manera: primer hemistiquio: $\cup--/---/ \cup \cup \cup / \cup \cup-/-U$ $\mathrm{U} / \mathrm{U}-/$, segundo hemistiquio: $\cup--/---/ \cup \cup \cup / \cup \cup-/-\cup \cup / U$ $-/$, tercer hemistiquio: $\cup--/---/ \cup \cup \cup / \cup \cup-/-\cup \cup / \cup-/$ y cuarto hemistiquio: $\cup--/---/ \cup \cup \cup / \cup \cup-/-\cup \cup / \cup-/$. De acuerdo con lo anterior, se estructura en cada hemistiquio por $y$ a o baquio $U--$, por $m a$ o moloso - - -, por $n a$ o tribraquio $\cup \cup \cup$, por $s a$ o antidáctilo $\cup \cup-$, por bha o dáctilo - $\cup \cup$ y por dos sílabas una breve la y otra larga ga, las cuales forman un pramānī o un yambo $U-.{ }^{29}$.

28 लंखिन्नास्ते भूर्म बहरिवनतः प्राणदयती नरिाहाराः सख्यः सततरुदतिच्छूननयनाः। परत्यिक्तं स्सवं हसतिपठतिं पज्जरशुकैस्तवावस्था चेयं वसृंज कठनि! मानमधुना॥ज॥ Amaruśatakam. 7.

29 Morgan, Les. Croaking Frogs, A guide to Sanskrit Metrics and Figures of Speech. (Los Ángeles: Mahodara Press. 2011). 148. 
No todo en la poesía de Amaru es sufrir y llorar, sino que también hay momentos de gozo, de un amor que lleva a los amantes a la pasión, quienes se regodean en tan bello sentimiento. Por ejemplo, en el siguiente poema hay una hermosa descripción de un encuentro de miradas de amor y deseo:

Cuando lo contemplo y me ve, me agacho

y miro la tierra; dejo de escuchar, aunque desee oír su voz y sus palabras; con mis manos oculto mi sudor que nace de mis mejillas erizadas.

Amigas, ¿qué debo hacer? Los bordes

de mi blusa se han desatado cientos de veces. ${ }^{30}$

Este poema es una descripción muy sutil del amor pasional de una mujer. Los ojos no sólo son la expresión de un amor oculto sino también juegan un papel determinante para entender las consecuentes del amor en la unión, ya que estos elementos caracterizan los sentimientos y los deseos de los amantes como la consecuencia del acto de contemplarse. Este poema está colmado del verdadero amor, porque se hallan dos elementos sumamente cargados de erotismo. Ejemplo de ello es cuando ella se cubre las mejillas erizadas llenas de sudor (en sánscrito pānibhyām ca tiraskrtạ sapulakah svedodramo gandayoh), la acción de contemplar a través de los ojos (drsțtih) introduce el deseo que Amaru disfraza dentro del sabor del erotismo que refuerza con el diálogo entre la mujer que ama con sus amigas explicando que los bordes de su blusa se han desatado cientos de veces planteando la siguiente pregunta retórica ¿qué debo hacer?, la cual supone una ruptura en el discurso entre la mujer amada y sus amigas, porque en realidad sabe lo que tiene que hacer (en sánscrito sakbyah kim karavāni yānti śatadhā yatkañcuke saimdhayah). Este poema hace que los sentimientos, los cuales son los determinantes tales como la pasión y el deseo, se esclarezcan como un amor tácito y puro lleno de erotismo. La consecuencia es que la mujer suda, hace que los bordes de su blusa se desaten

\footnotetext{
30 तद्वक्ताभमिखं मुखं वनिमतिं दृर्षः कृता पादयोस्तस्यालापकुतूहालाकुलतरे श्रोत्रे नरिद्धे मया। पाणभ्यिं च तरिस्कृतः सपुलकः स्वेदोद्रमो गण्डयोः सख्यः! क किवाणयिान्तशितधा यत्कज्चुके संधयः॥१ १॥ Amarusatakam. 11.
} 
y sus palabras provoquen un deseo ferviente tras contemplar a su amado y, por supuesto, el cuestionamiento que tiene que hacer; estos determinantes se unen a los consecuentes para expresar el amor a través de los ojos de ella y de él al momento del encuentro. En este encuentro de miradas (en

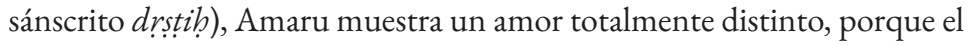
poema está fuera del sufrimiento y del llanto y lo disfraza de erotismo para poder saborear el amor en la unión. El verso que utiliza Amaru para expresar este amor erótico es el śārdülavikrídita, el cual está constituido por cuatro hemistiquios de diecinueve sílabas cada uno. Es uno de los versos más usados en la lírica sánscrita por su rapidez y dulzura. Tiene su cesura en la doceava sílaba y en la séptima del siguiente hemistiquio. Este verso se estructura de la siguiente manera: primer hemistiquio: - - - / U U - / $U-U / U \cup-/--U /--U /-$, segundo hemistiquio: - - - / U U - / $U-U / U \cup-/--U /--U /-$, tercer hemistiquio: - - - / U U - / $U-U / U U-/--U /--U /-$ y cuarto hemistiquio: - - - / U U - / $\mathrm{U}-\mathrm{U} / \mathrm{U} \cup-/--\mathrm{U} / \mathrm{-}-\mathrm{U} / \mathrm{-}$. El verso śärdūlavikrīdita pertenece al grupo de los atidhrti. Este verso se estructura en cada hemistiquio por $m a$ o moloso - - -, por $s a$ o antidáctilo $\cup \cup-$, por ja o amfíbraco $U-U$, por $s a$ o antidáctilo $\cup \cup-$, por $t a$ o antibaquio - $-U$, por $t a$ o antibaquio - $\cup$ y por una sílaba larga $g a-{ }^{31}$.

Leamos el siguiente poema muy similar al anterior:

$\mathrm{Al}$ ver a sus dos amadas sentadas en un mismo lecho, sutilmente se acercó por detrás; jugueteando cubrió los ojos de una de ellas; volteando levemente su cabeza, el muy canalla besó a la otra, cuyos vellos se erizaron de placer, mientras su corazón latió emocionado, una sonrisa oculta brilló en sus mejillas ${ }^{32}$.

31 Morgan, Les. Croaking Frogs, A guide to Sanskrit Metrics and Figures of Speech. 157.

32 दृष्ट्रैकासनसंस्थति प्रायितमे पश्चादुपेत्यादरादेकस्या नयने नमील्य वहितिक्रीडानुबन्धचूछलः। ईषद्वक्रतिकंधरः सपुलक: प्रेमोल्लसन्मानसामन्तर्हासलसत्कपोलफलकां धूरतो उपरां चुम्बताी९९॥ Amaruśatakam. 19. 
La estructura del verso anterior marca una realidad poética que nos conduce a la pasión y al erotismo, pues, ¿quién podría contemplar los ojos de dos hermosas mujeres sentadas en un mismo lecho? De acuerdo con esta pregunta, en este poema, la referencia de los ojos (nayana) juega un papel determinante, ya que, en el momento que el varón cubre los ojos de una de las doncellas (en sánscrito nayane nimìlya vibitakrị̀ānubandhacchalah), esa situación se torna en un amor que roza en el deseo y en la pasión. En este sentido, el amor que se presenta en este poema es un juego lírico que se traslada al terreno del sabor de lo erótico. El deseo y la pasión son los determinantes que se han unido a los consecuentes, para que una mujer, con los ojos cerrados, se regocije en el amor y la otra mujer se erice con su corazón pleno de emoción con sus ojos abiertos, lo cuales se alborocen con deseo y amor (en sánscrito ișdvakritakaìdharạ sapulakah premollasanmānasāmantarhāsalasatkapolaphalakām dhürto 'parāim cumbati). Una vez más Amaru utiliza el verso śārdülavikrídita para expresar un amor puesto en dos personas cargado de erotismo en la unión. Este verso está constituido por cuatro hemistiquios de diecinueve sílabas cada uno. Es uno de los versos más usados en la lírica sánscrita por su rapidez y dulzura. Tiene su cesura en la doceava sílaba y en la séptima del siguiente hemistiquio. Este verso se estructura de la siguiente manera: primer hemistiquio: $---/ U U-/ U-U / U U-/--U /--U /$ -, segundo hemistiquio: - - - / U U - / U - U / U U - / - - U / - - U / -, tercer hemistiquio: - - - / UU - / U - U / UU - / - - U / - - U / - y cuarto hemistiquio: - - - / U U - / U-U/UU - / - - U/ - - U / -. Como lo mencioné anteriormente, el verso śärdülavikrídita pertenece al grupo de los atidhrti. Este verso está estructurado en cada hemistiquio por $m a$ o moloso - - -, por $s a$ o antidáctilo $\cup \cup-$, por $j a$ o amfíbraco $U-U$, por $s a$ o antidáctilo $U U-$, por $t a$ o antibaquio $--U$, por $t a \mathrm{o}$ antibaquio - $-U$ y por una sílaba larga $g a-{ }^{33}$.

Amaru no sólo escribió poemas cargados de sufrimiento y llanto, de pasión y erotismo, sino también sobre un amor dulce, cándido y puro que también se entiende a partir de los ojos. En el siguiente poema se puede 33 Morgan, Les. Croaking Frogs, A guide to Sanskrit Metrics and Figures of Speech. 157. 
contemplar la transparencia y dulzura del amor a través de los ojos de una mujer enamorada que da la bienvenida a su amado:

Las largas guirnalda para el homenaje

no las confeccionó con lotos

sino con sus miradas;

los racimos de flores para la ofrenda

no los hizo con jazmines

sino con sus sonrisas;

las libaciones con agua para la prosperidad

no las realizó con un jarro

sino con sus turgentes senos sudorosos,

así, con su bello cuerpo,

la hermosa dio la bienvenida a su amado ${ }^{34}$.

Las guirnaldas son un símbolo de augurio y respeto muy especial en la India antigua, porque son la muestra del amor. En este poema, Amaru dice que las guirnaldas fueron hechas por las miradas dulces de una mujer. En este sentido, estas guirnaldas no sólo se forman con flores sino con las miradas de amor de una mujer que da la bienvenida a su amado (en sánscrito dìrghà vandanamālikā vicitā drștyaiva nendìvaraiḩ). Por ello, en estos primeros versos, Amaru hace una comparación entre las dulces miradas que provienen de los ojos emocionados de una mujer y los lotos azules ya que, unidas estas miradas a los encantadores lotos, ambas circunstancias se mezclan para formar un solo momento lleno de amor a través de la metáfora entre los rasgos físicos de buen augurio y las emociones, al encontrarse las sonrisas dulces que expresan un amor más callado y pasivo (en sánscrito puspānāàm prakaraḥ smitena racito no kundajātyādiubhih). Posteriormente, en los siguientes hemistiquios, Amaru se torna más explícito con los determinantes, porque comienza a describir el cuerpo de la mujer y menciona sus turgentes senos adornados con sudor y, en ese momento, llegaba su amante seducido por el cuerpo encantador de su mujer amada como la consecuencia (en sánscrito dattah svedamucā payodharabhareñārdho na kumbhāmbhasā svairevāvayavaih priyasya viśatastanvyā krtaim mañgalam). En este poema, Amaru hace un juego

34: दीघा वन्दनमालकि वचिति दृष्ट्यैव नेन्दीवरैः पुष्पाणां पकरः स्मतिन रचति नो कुन्दजात्यादभिः। दत्तः स्वेदमुचा पयोधरभरेर्णाघो न कुम्भाम्भसा स्वैरेवावयवैः पयिस्य वशितस्तन्व्या कृतं मड्गलम्॥४४॥ Amaruśatakam. 45. 
amoroso muy distinto al de los anteriores poemas, pues comienza con un amor dulce y sereno que se refleja en las dulces miradas de una mujer a través de sus ojos y termina con un amor pasional cuando Amaru describe la llegada de su amado y esta es la consecuencia que hace que surja el sabor del amor en la unión. Una vez más, Amaru utiliza el verso sárdūlavikrídita, el cual está constituido por cuatro hemistiquios de diecinueve sílabas cada uno. Tiene su cesura en la doceava sílaba y en la séptima del siguiente hemistiquio. Este verso se estructura de la siguiente manera: primer hemistiquio: $---/ \cup \cup-/ U-U / U \cup-/--U /--U /-$, segundo hemistiquio: $---/ \cup \cup-/ \cup-\cup / \cup \cup-/--\cup /--\cup /-$, tercer hemistiquio: $---/ \cup \cup-/ U-U / U \cup-/--U /--U /-$ y cuarto hemistiquio: $---/ \cup \cup-/ \cup-\cup / \cup \cup-/--U /--U /-$. Como lo mencioné anteriormente, el verso śārdūlavikrídita pertenece al grupo de los atidhrti. Este verso está estructurado en cada hemistiquio por ma o moloso - - -, por $s a$ o antidáctilo $\cup \cup-$, por $j a$ o amfíbraco $U-U$, por $s a$ o antidáctilo $U \cup-$, por $t a \mathrm{o}$ antibaquio $--U$, por $t a \mathrm{o}$ antibaquio - $\cup$ y por una sílaba larga $g a-{ }^{35}$.

En el siguiente poema, existe un amor puro sin ningún interés por parte de una mujer enamorada, la cual establece una conexión entre su sentir con sus ojos:

Cuando mi amor se desprendió de aquella pasión desbordada, desapareció el afecto que antes le inspiraba.

Ahora pasa ante mis ojos una y otra vez como si fuera cualquier persona extraña.

Así han trascurrido los días; querida amiga, no entiendo la razón del por qué mi corazón no florece ${ }^{36}$.

Este diálogo entre dos amigas es una forma de explicar el desamor que ha nacido en una de ellas y es una recurso muy recurrente para los poetas

35 Morgan, Les. Croaking Frogs, A guide to Sanskrit Metrics and Figures of Speech. 157.

36 'य गते पेमाबन्धे पणयबहुमाने वगिलति नवृत्ते सद्धावे जन इव जने गच्छत पुरः। तुुत्प्पेक्योत्पेक्ष्य पयिसखा? गतांस्तांश्च दविसान्न जाने को हेतुद्यलतशितधा यन्न हृदयम॥४३॥ Amarusatakam. 43. 
sánscritos quienes utilizan para expresar el desamor. Es claro que existe una gran indiferencia por parte del amado. En consecuencia, la mujer sufre, porque, cuando lo ve pasar frente a ella, sus ojos son el vínculo entre el amor y el desamor, es decir, ella sólo lo ve, pero él a ella no (en sánscrito gate premābandhe pranayabahumāne vigalite nivrtte sadbhāve jana iva jane gacchati purah). Amaru pinta esta escena para expresar un amor lleno de extrañeza y añoranza como los determinantes, los ojos juegan un papel fundamental porque hacen contacto con los sentimientos que establecen los consecuentes del sabor del amor en la separación. Asimismo, él, por su parte, ya no siente aquel amor que le hacía sentir devoción por ella. En este sentido, cuando él la ve, sus ojos se muestran indiferentes y distantes. De esta explicación nace la razón del por qué su corazón no florece más entendido a través del diálogo con su más querida amiga y ésta es la consecuencia para degustar el sabor del amor en la separación (en sánscrito tadutpreksyotpreksya ipriyasakhi! gatāmstāmiśca divasānna jāne ko heturdalati satadhà yanna hrdayam). El verso que utiliza Amaru en este poema es el śikharinīi, el cual está constituido por cuatro hemistiquios de diecisiete sílabas cada uno. Éste es uno de los versos más usados en la lírica sánscrita por su lentitud y cadencia. Tiene su cesura en la sexta sílaba y en la onceava. Este verso se estructura de la siguiente manera: primer hemistiquio: $\cup--/---/ \cup \cup \cup / \cup \cup-/-\cup \cup / \cup-$, segundo hemistiquio: $\cup--/---/ \cup \cup \cup / \cup \cup-/-\cup \cup / \cup-$, tercer hemistiquio: $\cup--$ / $---/ \cup \cup \cup / \cup \cup-/-\cup \cup / \cup-$ y cuarto hemistiquio: $\cup--/---/$ $\cup \cup \cup / \cup \cup-/-\cup \cup / U-$. El verso śikharin̄i pertenece al grupo de los atyasți. Este verso se estructura en cada hemistiquio por ya o baquio $U-$ -, por ma o moloso - - -, por $n a$ o tribraquio $\cup \cup \cup$, por $s a$ o antidáctilo $\cup \cup-$, por bha o dáctilo - $\cup \cup$ y por dos sílabas una breve la y otra larga ga, las cuales forman un pramāñ̄ o un yambo $U-{ }^{37}$.

El siguiente poema es otro ejemplo de la importancia de los ojos que expresan un amor iracundo dentro del sabor del amor en la unión:

37 Morgan, Les. Croaking Frogs, A guide to Sanskrit Metrics and Figures of Speech. 148. 


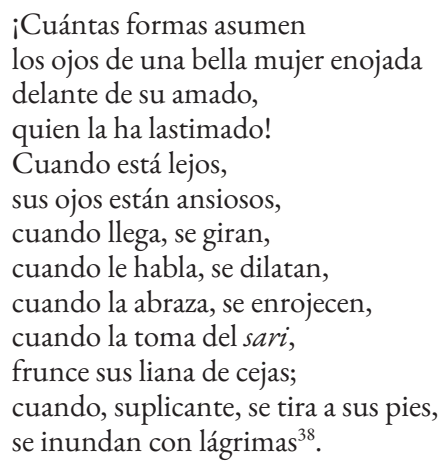

Amaru, en las primeras palabras, se ve sorprendido por las diferentes formas que adoptan los ojos, consecuentes por las ofensas de un varón, porque, aunque la mujer se sienta enojada, los ojos son realmente los que hablan, si los ojos no ven al ser amado están ansiosos, desesperados, si él le habla se dilatan por amor, deseo y si él la abraza se sienten tristes y lloran (en sánscrito dūrādutsukamāgate vivalitaì sambhāsinini sphāritaim saimślisyatyarunami grhittavasane kopāñcitabhrülatam). Me parece que estos determinantes describen una situación sentimental que hace que los ojos se vuelvan más sutiles en este poema, ya que existe una dedicatoria a los ojos que vislumbran un amor en tres diferentes facetas: la cólera de la mujer por una ofensa, la acción que hace que el fuego de sus ojos se muestre más expresivos y la reacción que describe los diferentes sentimiento como la cólera, el deseo y el llanto (en sánscrito māninyāścaraṇānativyatikare bāspāmbupürṇekșañàin cakșurjātamaho prapañcacaturaì jātāgasi preyasi). Estos tres aspectos son los consecuentes que hacen que el poema se enmarque en el sabor del amor en la unión. Nuevamente Amaru utiliza el verso sárdūlavikrìdita para expresar un amor cargado de celos, sufrimiento y enojo. Este verso está constituido por cuatro hemistiquios de diecinueve sílabas cada uno. Tiene su cesura en la doceava sílaba y en la séptima del siguiente hemistiquio. Este verso se estructura de la siguiente manera: primer hemistiquio: $\quad---/ U U-/ U-U / U U-/--U$

38 दूरादुत्सुकमागते वविलतिं संभाषणि स्फारतिं संश्लष्यित्यरुणं गृहीतवसने कोपाज्चतिभूलतम 'मानन्यिाश्चरणानतव्यितकिरे बाष्पाम्बुर्पूणेक्षणां चर्क्षुजातमहो पपज्चचतुरं जातागसप्पेयसति४९॥ Amarusatakam. 49. 
/ - - U / -, segundo hemistiquio: - - - / U U - / U - U / U U - / - - U

/ - - U / -, tercer hemistiquio: - - - / U U - / U - U / U U - / - - U

/ - - U / - y cuarto hemistiquio: - - - / U U - / U - U / U U - / - - U

/ - - U / -. Como lo mencioné anteriormente, el verso śärdülavikrìdita pertenece al grupo de los atidhrti. Este verso está estructurado en cada hemistiquio por $m a$ o moloso - - -, por $s a$ o antidáctilo $\cup \cup-$, por $j a \mathrm{o}$ amfíbraco $U-U$, por $s a$ o antidáctilo $U \cup-$, por $t a$ o antibaquio $--U$, por ta o antibaquio - $-U$ y por una sílaba larga $g a-{ }^{39}$.

\section{Conclusiones}

Respondiendo la pregunta que me llevó al análisis del pensamiento de Amaru: ¿realmente son los ojos trasmisores del śringārarasa en la poesía de Amaru?, estos poemas son el ejemplo claro de la teorización del amor que se estructura en la poesía de Amaru bajo los lineamientos de la teoría del rasa. Es evidente que los amantes o los protagonistas son quienes envuelven al lector en la dinámica literaria del sabor del amor tanto en la unión como en la separación a través de los ojos. Siempre se encuentran enternecidos por el amor o enojados o bien indiferentes ya que recrea la pasión humana que silenciosamente muestran los determinantes como los besos, los labios temblorosos, las caricias, las indiferencias, los celos etc. Para determinar los consecuentes, los ojos son el vehículo humano que describen las situaciones y las vicisitudes que Amaru mezcla con las emociones de los amantes y las situaciones donde se desenvuelven y desarrollan literariamente. Este detalle es el núcleo de los poemas, porque no sólo son las palabras las que expresan el deseo ferviente del amor, sino su significado junto con los ojos habla en los poemas para irradiar y saborear la esencia del amor. En este sentido, lo más importe se centra en el sabor del amor que se prueba a través de sus ojos.

De acuerdo con lo anterior, el mecanismo con que opera la actividad fisiológica que realizan los ojos me ha permitido degustar el sabor del amor en la poesía que se percibe transformando el amor en los amantes

39 Morgan, Les. Croaking Frogs, A guide to Sanskrit Metrics and Figures of Speech. 157. 
dentro de la poesía de Amaru. Esta transformación percibe las reacciones corporales y las actitudes de las personas involucradas en el mundo del amor. Los ojos son el contacto con todo lo que yace y subyace, con lo real y lo irreal, con lo racional e irracional en el mundo. De este modo, el conocimiento de las diferentes manifestaciones del amor reflejado en los ojos atrapa la luz de los sentimientos que se conducen dentro de la pasión y hacen que estas alusiones del amor en los poemas de Amaru sean mucho más sencillas y menos complicadas de entender. En la poesía de Amaru, muchas palabras se han transformado para permanecer en el lenguaje del sabor del amor y de los distintos sentimientos que expresan sus significados dentro de su poesía. A partir de aquí, se ha generado una especie de código en los ojos dentro de la poesía sánscrita, donde determinadas comparaciones son indispensables para identificar los significados de las expresiones de los amantes. Por ello, el amor que expresan los ojos en la poesía de Amaru está fundamentada por la teoría del rasa, no sólo por la función descriptiva que realizan sino por el empleo central que representa el poema, es decir, el contacto visual, que existe en la poesía de Amaru, hace que el amor, en sus muchas manifestaciones, fluya a través de los ojos en los amantes y se logre degustar gracias a los determinantes y a los consecuentes. Es en este momento, donde Amaru se desprende de lo racional y se traslada al terreno de lo irracional, pues, al escribir su poesía, se muestra muy ecuánime y congruente con sus sentimientos al ser el mediador entre el amor y la vivencia de los amantes vista con sus propios ojos. Por esta razón, los ojos se han convertido, en la poesía sánscrita, los mediadores de tan bello sentimiento, para que podamos degustarlo dentro del imaginario poético de Amaru.

\section{Referencias bibliográficas}

Amaru. Amarusatakam. Texto sánscrito con comentarios rasikasanjeevini de Arjunavarmadeva. Editado con comentarios y traducción en hindi por Shri Pradyumma Pandeya con una introducción de Shri Narayan Mishra. Varanasi: Chowkhamba Sanskrit Series Office. 2000. 
Amaru. Cien poema de amor. Versión directa del sánscrito de Fernando Tola. Barcelona: Barral editores. 1971.

Atharvaveda Sambitā. Vv. III. Texto sánscrito, traducción al inglés, notas e índice de versos de acuerdo con la traducción del inglés de W.D. Whitney y Bhāṣya de Sāyaṇācārya. Editado y revisado por K. L. Joshi. Nueva Delhi: Primal Publications. 2015.

Beristáin, Helena. Análisis e interpretación del poema lírico. México: Universidad Nacional Autónoma de México. 2004.

Bharata. Nātyaśāstra. Vv. IV. (Tratado de la India Antigua sobre la representación histriónica y la dramaturgia). Editado y traducido con una introducción y varias lecturas por Manomohan Ghosh. Varanasi: Chowkhamba Sanskrit Series Office. 2009.

Gutiérrez, Salvador, Ordóñez. Comentario pragmático de textos literarios. Madrid: Arco libros, S. L. 2000.

De, Kumnar, Sushil. Ancient Indian erotics and erotic literature. Calcuta: Firma K. L. Mukhopadhyay. 1969.

López, Eire, Antonio. Retórica clásica y teoria literaria moderna. Madrid: Arco libros, S. L. 1997.

Vyāsa. Mahābhārata. Traducido por Paul Wilmot, William J. Johnsom, Kathleen Garbutt, Alex Cherniak, Vaughan Pilikian, Adam Bowles, Justin Meiland, Alexandre Wynne and Kate Crosby. Vv. XV. Nueva York: New York University Press. 2006.

Maillard, Chantal y Óscar Pujol. Rasa, el placer estético en la tradición india. Prólogo de Raimon Panikkar. Varanasi: Indica Etnos. 1999.

Morgan, Les. Croaking Frogs, A guide to Sanskrit Metrics and Figures of Speech. Los Ángeles: Mahodara Press. 2011.

Mylius, Klaus. Historia de la literatura india antigua. Traducción de David Pascual Coello. Revisión de Ricardo Dorado Puntch y Antonio de Cabo de la Vega. Madrid: Trotta. 2015.

Reyes, Graciela. El abecé de la pragmática. Madrid: Arco libros, S. L. 2003. 
Rgveda Sambitāa. Vv. IV. Texto sánscrito, traducción al inglés y notas de acuerdo con la traducción H. H Wilson y Bhāṣya de Sāyanāāārya. Editado y revisado con una exhaustiva introducción y notas de Ravi Prakash Arya K. L. Joshi. Nueva Delhi: Primal Publications. 2016.

Upanișads. Prólogo de Raimon Panikkar y edición de Daniel de Palma. Madrid: Siruela. 2006.

Viñas, Piquer, David. Historia de la crítica literaria. Barcelona: Editorial Ariel, S. A. 2002.

Yedukondalu, K. Cassical Sanskrit Prosody. Tirupati: Rashtriya Sanskrit Vidyapeetha. 2014. 